\title{
Evaluation of Transplanted Tissue-Engineered Oral Mucosa Equivalents in Severe Combined Immunodeficient Mice*
}

\author{
KENJI IZUMI, D.D.S., Ph.D., ${ }^{1}$ STEPHEN E. FEINBERG, D.D.S., M.S., Ph.D., 1 \\ HIROTO TERASHI, M.D., Ph.D., ${ }^{2}$ and CYNTHIA L. MARCELO, Ph.D. ${ }^{2}$
}

\begin{abstract}
The aim of this study was to determine the optimal stage of development at which transplant human ex vivo-produced oral mucosa equivalents (EVPOMEs) in vivo. EVPOMEs were generated in a serum-free culture system, without the use of an irradiated xenogeneic feeder layer, by seeding human oral keratinocytes onto a human cadaveric dermal equivalent, AlloDerm. EVPOMEs were cultured for 4 days submerged and then for 7 or 14 days at an air-liquid interface to initiate stratification before transplantation into SCID mice. AlloDerm, without epithelium, was used as a control. Mice were killed on days 3, 10, and 21 posttransplantation. Epithelium of the transplanted EVPOMEs was evaluated with the differentiation marker keratin 10/13. Dermal microvessel ingrowth was determined by immunohistochemistry with a mouse vascular marker, lectin binding from Triticum vulgaris. The presence and stratification of the epithelium were correlated with revascularization of the underlying dermis. The microvessel density of AlloDerm without epithelium was less than that of EVPOMEs with an epithelial layer. Microvessel density of the dermis varied directly with the degree of epithelial stratification of the EVPOMEs. The EVPOMEs cultured at an air-liquid interface for 7 days had the optimal balance of neoangiogenesis and epithelial differentiation necessary for in vivo grafting.
\end{abstract}

\section{INTRODUCTION}

$\mathbf{S}$ INCE O'Connor AND Others ${ }^{1}$ first reported the use of cultured autologous epithelial sheets in patient care, there have been numerous clinical trials to study the treatment of large wounds with cultured epidermal cell sheets. ${ }^{2-4}$ These investigators reported that cultured autografts of keratinocytes had persistent problems, which included blistering, wound contracture, susceptibility to infection, and varying graft "take" rate. The problems were most likely due to the lack of a dermal component and of a mature dermoepidermal junction. ${ }^{5,6}$ To overcome these adverse events, artificial dermal substitutes have been used to assist in keratinocyte growth. ${ }^{7-12}$ One dermal analog used for treatment of full-thickness wounds is an acellular human cadaver dermis, AlloDerm (LifeCell, Branchburg, NJ).

AlloDerm is a durable acellular dermis, which retains extracellular matrix proteins and an intact basement membrane structure, while being surgically manageable. Several investigations have reported on the use of either AlloDerm or deepidermized human dermis in the devel-

\footnotetext{
${ }^{1}$ Department of Oral and Maxillofacial Surgery, University of Michigan Medical Center, Ann Arbor, Michigan.

${ }^{2}$ Section of Plastic and Reconstructive Surgery, University of Michigan Medical Center, Ann Arbor, Michigan.

*This investigation was performed at the Sections of Oral and Maxillofacial and Plastic and Reconstructive Surgery, Department of Surgery Laboratories, University of Michigan Health Science Center, Ann Arbor, Michigan. Parts of this investigation were presented at the American Association of Oral and Maxillofacial Surgeons Annual Meeting in Boston, September $29,1999$.
} 
opment of reconstituted skin and oral mucosa. ${ }^{13-17} \mathrm{We}$ reported on the characteristics of an ex vivo-produced oral mucosa equivalent (EVPOME) utilizing AlloDerm in a serum-free, defined medium, without an irradiated xenogeneic feeder layer. ${ }^{18}$

In preparation for human clinical trials it was necessary to optimize the culture protocol for the in vivo grafting of EVPOME. In this investigation, we evaluated EVPOME by transplanting it into immunologically compromised (SCID, severe combined immunodeficient) mice, using the technique of Barrandon et al. ${ }^{19}$ which places the graft into a subcutaneous dorsal skin pouch of athymic mice. The revascularization process that occurs at the recipient transplantation site is a main predictor of free graft survival. Thus, the main objective of this investigation was to correlate epithelial cell viability, stratification, and differentiation with vascular ingrowth (microvessel density) into the underlying dermal component, AlloDerm, to determine the optimal time necessary to culture EVPOME, in vitro, before grafting into the oral cavity.

\section{MATERIALS AND METHODS}

\section{Production of ex vivo-produced oral mucosa equivalent}

Cultures of human oral mucosa keratinocytes and ex vivo production of oral mucosa equivalents (EVPOMEs) were generated in a serum-free culture system without the use of an irradiated xenogeneic feeder layer, as described previously. ${ }^{18}$ Briefly, human oral keratinocytes were generated and amplified from trypsinized discarded human oral mucosa obtained by routine dentoalveolar surgical procedures. AlloDerm (LifeCell) was rehydrated in phosphate-buffered saline (PBS) $1 \mathrm{~h}$ before use. Harvested and expanded human oral keratinocytes, cultured in a $0.15 \mathrm{mM} \mathrm{Ca}^{2+}$, serum-free MCDB-153 complete medium, supplemented with hydrocortisone, insulin, epidermal growth factor (EGF), and bovine pituitary extract, were seeded at a density of $1.25 \times 10^{5}$ keratinocytes per square centimeter onto rehydrated AlloDerm coated with type IV collagen (Life Technologies, Gaithersburg, MD). The keratinocyte-AlloDerm composites were cultured submerged in $1.8 \mathrm{mM} \mathrm{Ca}^{2+}$-supplemented MCDB-153 complete medium for 4 days (D4E) and then at an airliquid interface for an additional 7 days (D11E) or 14 days (D18E) to enhance stratification of the epithelial layer of the EVPOMEs before grafting onto SCID mice. Only primary cells, from the first passage, were used to fabricate the EVPOMEs for surgical transplantation into mice. Each of the three transplantation groups received primary donor cells from two individuals. This allowed the generation of sufficient primary oral keratinocytes to perform each of the three experiments in this investiga- tion. The three donors used to fabricate the EVPOME grafts were two females, 62 and 64 years old, and a 55year-old male.

\section{Transplantation of ex vivo-produced oral mucosa equivalent into SCID mice}

The University of Michigan Committee on Use and Care of Animals approved all animal studies. The grafts were transplanted into dorsal subcutaneous pouches made in 7- to 8-week-old SCID mice, strain C.B-17/IcrTacscidfDF (Taconic, Germantown, NY). Mice were anesthetized by inhalation anesthesia (methoxyflurane [Metofane]; Pittman-Moore, Mundelein, IL). The dorsal skin of mice was disinfected with $95 \%$ ethanol. A full-thickness curvilinear incision was made down to the panniculus carnosus to create a subcutaneous pouch approximately 1.5 to $2.0 \mathrm{~cm}^{2}$ in size to accommodate the $1.0-\mathrm{cm}^{2}$ equivalents. Grafts were transferred to a subcutaneous pouch and overlaid with a circular piece of gassterilized biomedical-grade silicone sheeting, 0.005 in. thick (Specialty Manufacturing, Saginaw, MI) to prevent adherence of the epithelial layer of the EVPOME to the overlying connective tissue of the subcutaneous pouch. The open reticular portion of the AlloDerm of the EVPOME was grafted face down toward the muscular fascia. AlloDerm, without an epithelial layer, was used as a control. Experimental groups consisted of day 4, 11, and 18 equivalents (D4E, D11E, and D18E, respectively). Mice were killed on days 3, 10, and 21 postgrafting. Five AlloDerm controls (no epithelial layer) and 15 D4E mice were killed on each of postgrafting days 3,10 , and 21 whereas 10 mice were killed 3, 10, and 21 days postgrafting for the D11E and D18E EVPOMEs (Table 1).

\section{Histology and immunohistochemistry}

Retrieved EVPOMEs were fixed with $10 \%$ formalin and embedded in paraffin for histologic examination. Specimens were cut into $5-\mu \mathrm{m}$ sections and stained with hematoxylin and eosin. Immunostaining for keratin $10 / 13$, a differentiation marker, was performed with

Table 1. Number of SCID Mice used for Each Time Point in EVPoMe in Vivo Grafting Protocol

\begin{tabular}{lrrr}
\hline & \multicolumn{3}{c}{ Days postgrafting } \\
\cline { 2 - 4 } Type of graft & 3 & 10 & 21 \\
\hline Control $^{\mathrm{a}}$ & 5 & 5 & 5 \\
Day 4 equivalent (D4E) & 15 & 15 & 15 \\
Day 11 equivalent (D11E) & 10 & 10 & 10 \\
Day 18 equivalent (D18E) & 10 & 10 & 10 \\
\hline
\end{tabular}

Abbreviation: EVPOME, Ex vivo-produced oral mucosa equivalent.

${ }^{a}$ AlloDerm with no epithelial layer. 
avidin-biotin-peroxidase complex (ABC) as described previously. ${ }^{18}$

For detection of mouse vascular endothelial cells, immunohistochemical staining for Triticum vulgaris (wheat germ agglutinin, WGA) lectin binding was used to determine revascularization by counting the number of microvessels within the dermal component. ${ }^{20}$ Sections were first treated with $2 \%$ hydrogen peroxide in methanol for $30 \mathrm{~min}$ to inhibit endogenous peroxidase, followed by $10 \%$ bovine serum albumin (BSA; Sigma, St. Louis, MO) for $1 \mathrm{~h}$. The sections were then incubated with biotinylated WGA antibody (Sigma), diluted 1:20 in 1\% BSA, for $1 \mathrm{~h}$ at $37^{\circ} \mathrm{C}$ and washed in phosphate-buffered saline (PBS), followed by the ABC method (Vector Laboratories, Burlingame, CA) for $10 \mathrm{~min}$. A solution of peroxidase substrate 3,3'-diaminobenzidine tetrahydrochloride was used for visualization of the resulting complex. The specificity of the immunoreactants was assessed by replacement of biotinylated WGA with sugar or PBS.

\section{Evaluation of vascularity and statistical analysis}

To evaluate revascularization in each sample WGA lectin immunohistochemistry was used to assist in quantifying the number of invading endothelial cells. Because single endothelial cells as well as some fibroblasts and macrophages were immunopositive for WGA, only lumens encircled by immunopositive cells were used to identify microvessel density that is indicative of neoangiogenesis and revascularization of the AlloDerm. In accordance with the protocol used by Weidner et al. ${ }^{21}$ the highest number of vessel lumens within any $\times 200$ field was represented as the vessel count of the sample. Comparisons between groups were evaluated by a MannWhitney $U$ test. Values of $p<0.05$ were considered to be statistically significant.

\section{RESULTS}

\section{Histologic analysis of EVPOME}

In vitro

AlloDerm grafts without epithelium consisted of dense collagen fibrils and an undulating papillary surface (Fig. 1a). AlloDerm grafts with epithelium (EVPOME) formed a continuous keratinocyte monolayer when cultured for 4 days submerged (D4E; Fig. 1b). When the D4E grafts were raised to an air-liquid interface for 7 days (D11E) the epithelial layer began to stratify and show evidence of parakeratinization (Fig. 1c). After 14 days at an airliquid interface (D18E) there was a continued increase in stratification and differentiation of the epithelium (Fig. 1d). Keratin 10/13, a differentiation marker, usually expressed by cells in the suprabasal layer of oral mucosa, was not expressed in D4E or D11E (Fig. 2a and b). In D18E it was visible only in the superficial layer (Fig. 2c).

\section{Grafting to SCID mice}

AlloDerm without epithelium. In the control AlloDerm graft, without an epithelial layer, at 3 days postgrafting
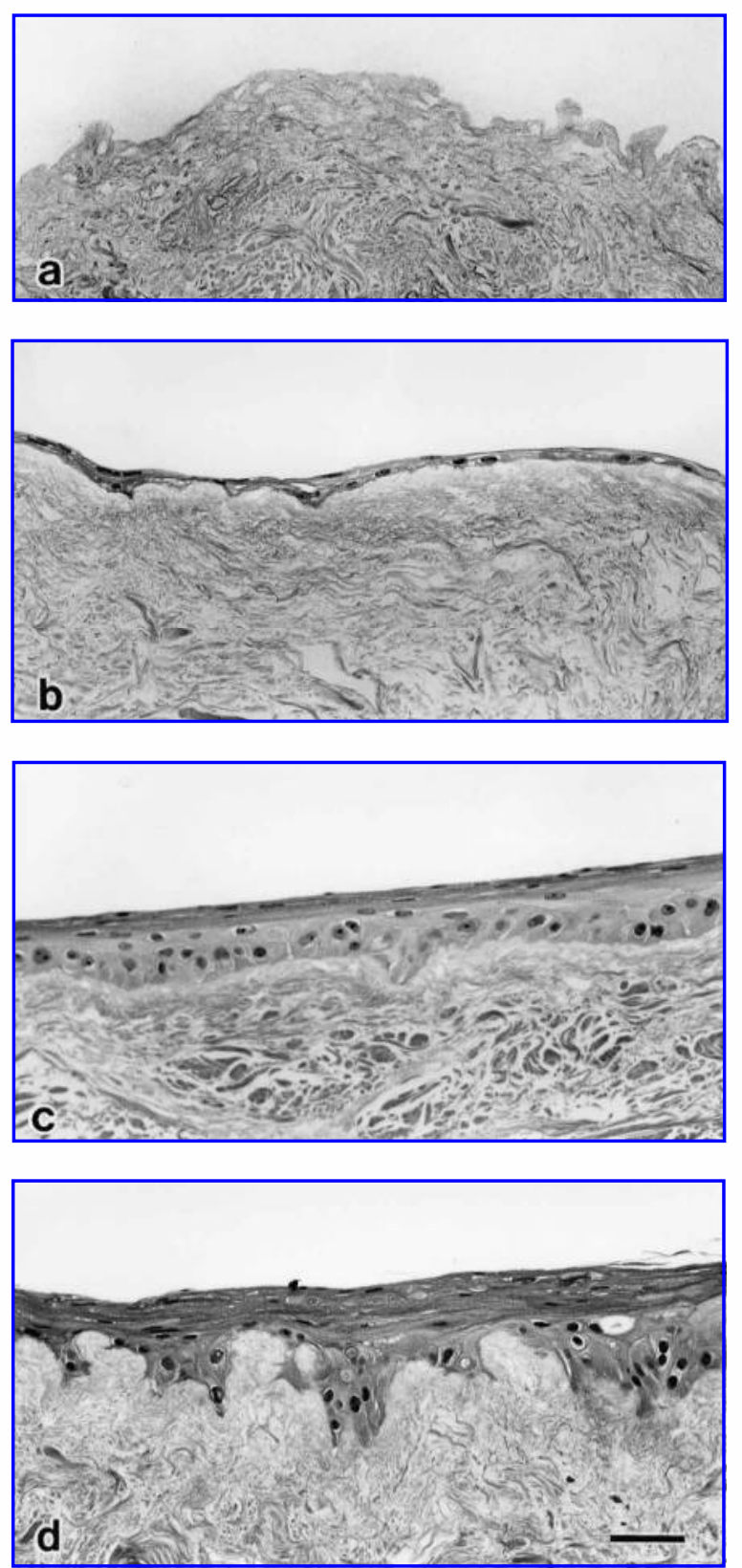

FIG. 1. Histologic findings of unseeded acellular dermis, AlloDerm, and ex vivo-produced oral mucosa equivalents before transplantation. (a) Rehydrated acellular AlloDerm with dense collagen bundles. (b) Epithelial monolayer of D4E. (c) Increase in epithelial stratification of D11E and (d) D18E after culturing at an air-liquid interface for 7 and 14 days, respectively. (Hematoxylin and eosin staining; original magnification, $\times 250$; scale bar, $50 \mu \mathrm{m}$.) 

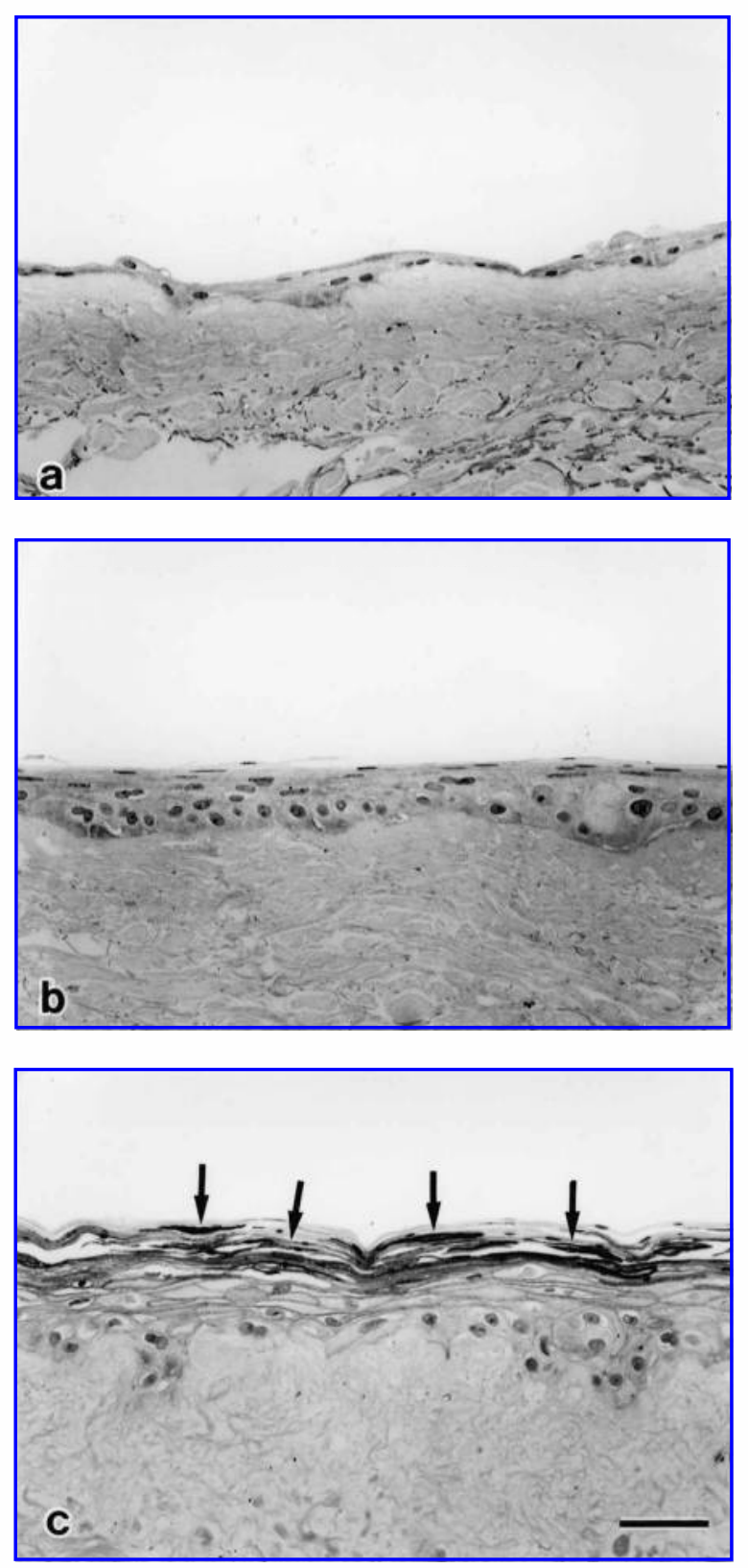

FIG. 2. Immunohistologic findings of ex vivo-produced oral mucosa equivalents before transplantation. Keratin 10/13 expression is not seen in (a) D4E or in (b) D11E. (c) In D18E, it is present only in the superficial layer (arrows). (Original magnification, $\times 300$; scale bar, $50 \mu \mathrm{m}$.)

in vivo, a few spindle-shaped cells, similar to fibroblasts and/or endothelial cells, were seen infiltrating into the portion of the AlloDerm that was in direct contact with the underlying muscular layer (Fig. 3a). Cellular infiltration into the AlloDerm gradually increased in number in day 10 and 21 postgrafting transplants, but was localized at the base (Fig. $3 \mathrm{~b}$ and c). At postgrafting day 21 there was evidence of infiltrating cells present in the superficial or upper portion of the AlloDerm; however, vascularization was scarcely seen at the base or lower portion.

Day 4 equivalent. The epithelial monolayer of grafted D4E began to stratify at postgrafting day 3 (Fig. 4a). At day 3 postgrafting the D4E showed an increase in the number of fibroblasts and endothelial cells infiltrating
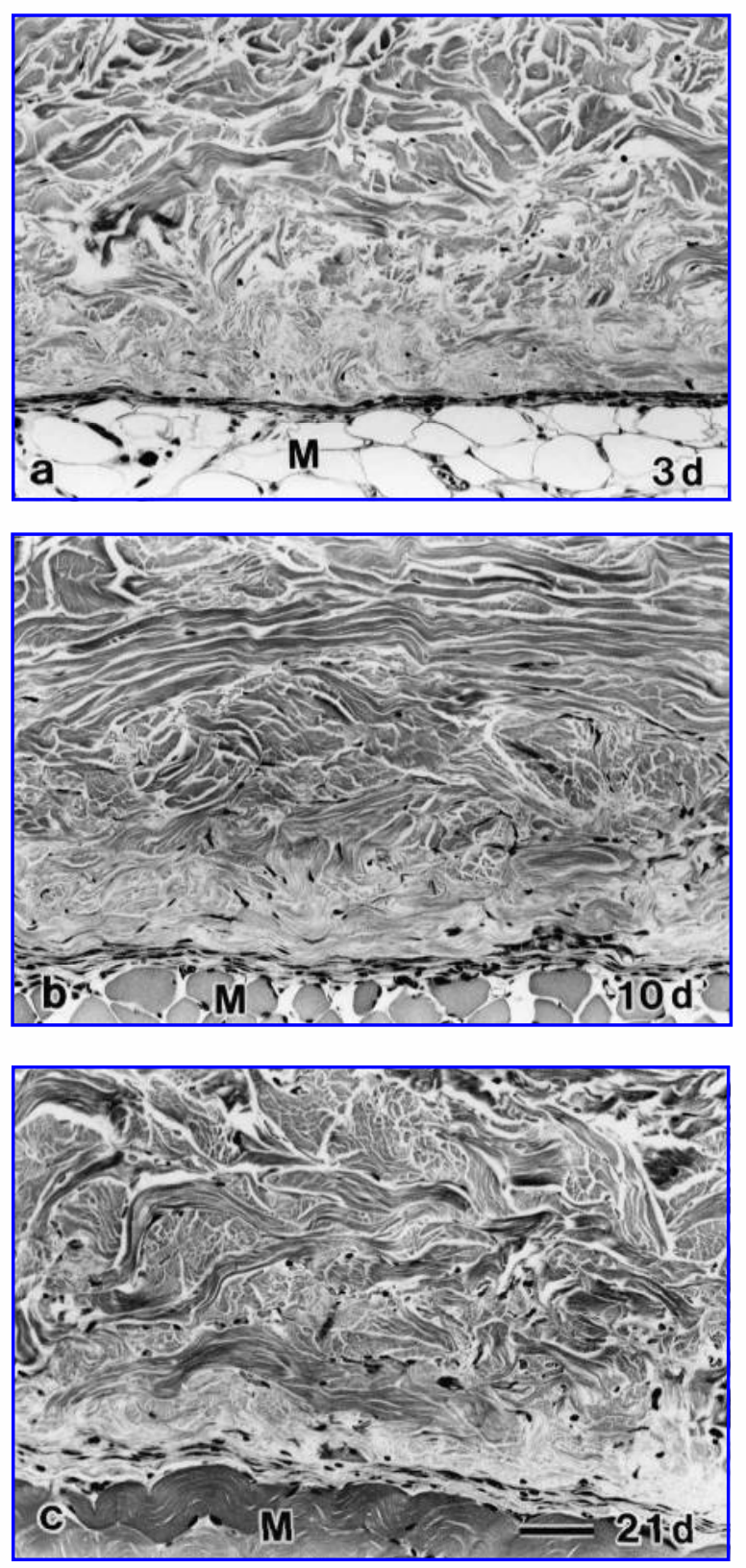

FIG. 3. Histologic analysis of grafted AlloDerm without an epithelial layer: Postgrafting day 3 (a), day 10 (b), and day 21 (c). Cells infiltrating into the AlloDerm gradually increased in number at the base of the dermis from day 3 to day 21 postgrafting transplants (a-c). By postgrafting day 21 (c) there was evidence of infiltrating cells present in the superficial or upper portion of the AlloDerm, but vascularization was scarcely evident. M, Underlying muscle layer. (Hematoxylin and eosin staining; original magnification, $\times 250$; scale bar, $50 \mu \mathrm{m}$.) 

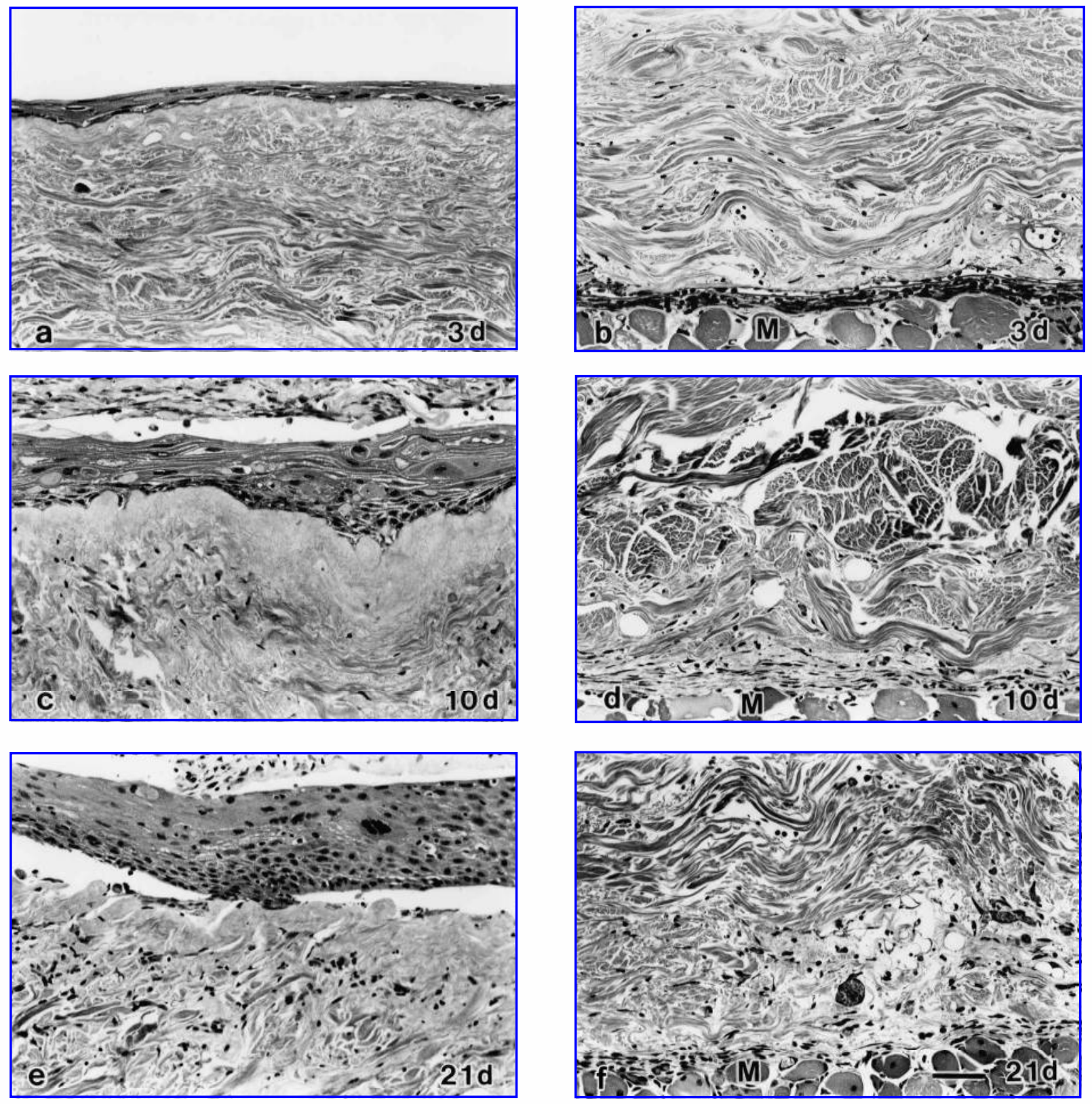

FIG. 4. Histologic analysis of grafted D4E: Postgrafting day 3 (a and b), day 10 (c and d), and day 21 (e and f); epithelial layer (a, c, and e) and dermal portion (b, d, and $\mathbf{f}$ ) of grafted equivalents. The epithelial monolayer of D4E, immediately after grafting, continues to stratify over time from day 3 to day 21 (a, c, and e). Cellular ingrowth throughout the dermis is rapid compared with controls, as seen by evidence of infiltrating spindle-shaped and rounder cells at days 3 and 10 postgrafting (b and d). At day 21 after grafting, numerous blood vessels, filled with erythrocytes, are seen within loosely arranged and disorganized collagen bundles at the base of the dermis (f). M, Underlying muscle layer. (Hematoxylin and eosin staining; original magnification, $\times 250$; scale bar, $50 \mu \mathrm{m}$.)

throughout the underlying AlloDerm, in contrast to the AlloDerm control (Fig. 4b). At postgrafting day 10 epithelial stratification and differentiation continued to increase in D4E and was comparable to what was seen in vitro in pregrafted D18E (Fig. 4c; compare with Fig. 1d). Infiltrating spindle-shaped fibroblasts and a rounder cell infiltration, indicative of revascularization, were more prominent within the lower or basal portion of the dermis in D4E at 10 days postgrafting when compared with AlloDerm controls (Fig. 4d). At day 21 postgrafting, the epithelium of D4E continued to stratify (Fig. 4e). This directly correlated with an increase in cell infiltration and associated revascularization within the dermis over the day 10 postgrafting specimens (Fig. 4f). 
Day 11 equivalent. The epithelial layer of D11E, at postgrafting days 3 and 10, continued to stratify and differentiate (Fig. 5a and c). An increase in fibroblastic and endothelial cell infiltration was seen at the dermalmuscle interface at day 3 postgrafting (Fig. 5b). A marked increase in cellular infiltration and revascularization throughout the entire dermis was seen at day 10 postgrafting (Fig. 5c and d). The infiltration and revas- cularization were more pronounced than observed in D4E at similar time intervals postgrafting. At day 21 postgrafting the highly keratinized and stratified epithelial layer showed signs of degeneration (Fig. 5e). The breakdown in the epithelial layer in D11E coincided with a decrease in the cellular infiltration and vascularity within the dermis subjacent to the epithelium but cellular infiltration was still evident, however, within the basal or
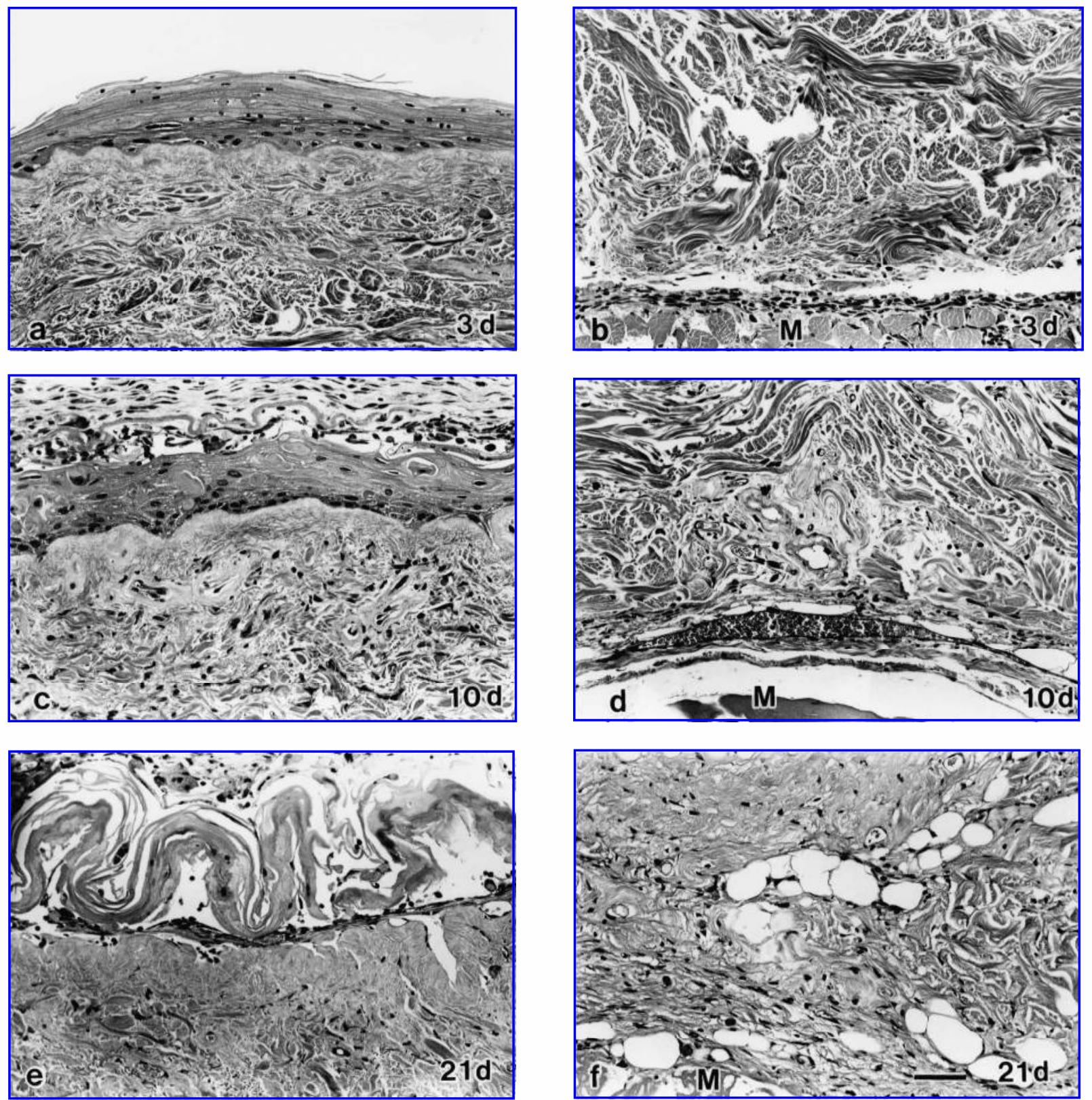

FIG. 5. Histologic analysis of grafted D11E: Postgrafting day 3 (a and b), day 10 (c and d), and day 21 (e and f); epithelial (a, c, and e) and dermal (b, d, and $\mathbf{f}$ ) portions of the grafted equivalents. The thin epithelial layer continued to stratify and differentiate at day 3 postgrafting (a) and peaked in stratification at day 10 postgrafting (c). Numerous plump fibroblasts appear subjacent to the epithelial layer at day 10 postgrafting (c). A large number of microvessels are observed within the lower portion of the dermis (d). At day 21 postgrafting, the stratified and highly keratinized epithelial layer begins to show signs of degeneration (e). In the dermal component there is a random arrangement of the collagen bundles associated with adipose-like tissue (f). M, Underlying muscle layer. (Hematoxylin and eosin staining; original magnification, $\times 250$; scale bar, $50 \mu \mathrm{m}$.) 
lower portion of the dermis with evidence of lumenous structures (Fig. 5f).

Day 18 equivalent. D18E, at 3 days postgrafting, showed signs of marked keratinization and degeneration of the epithelial layer (Fig. 6a). This correlated with a marked increase in fibroblastic and endothelial cell infiltration seen at the inferior and superior portions of the
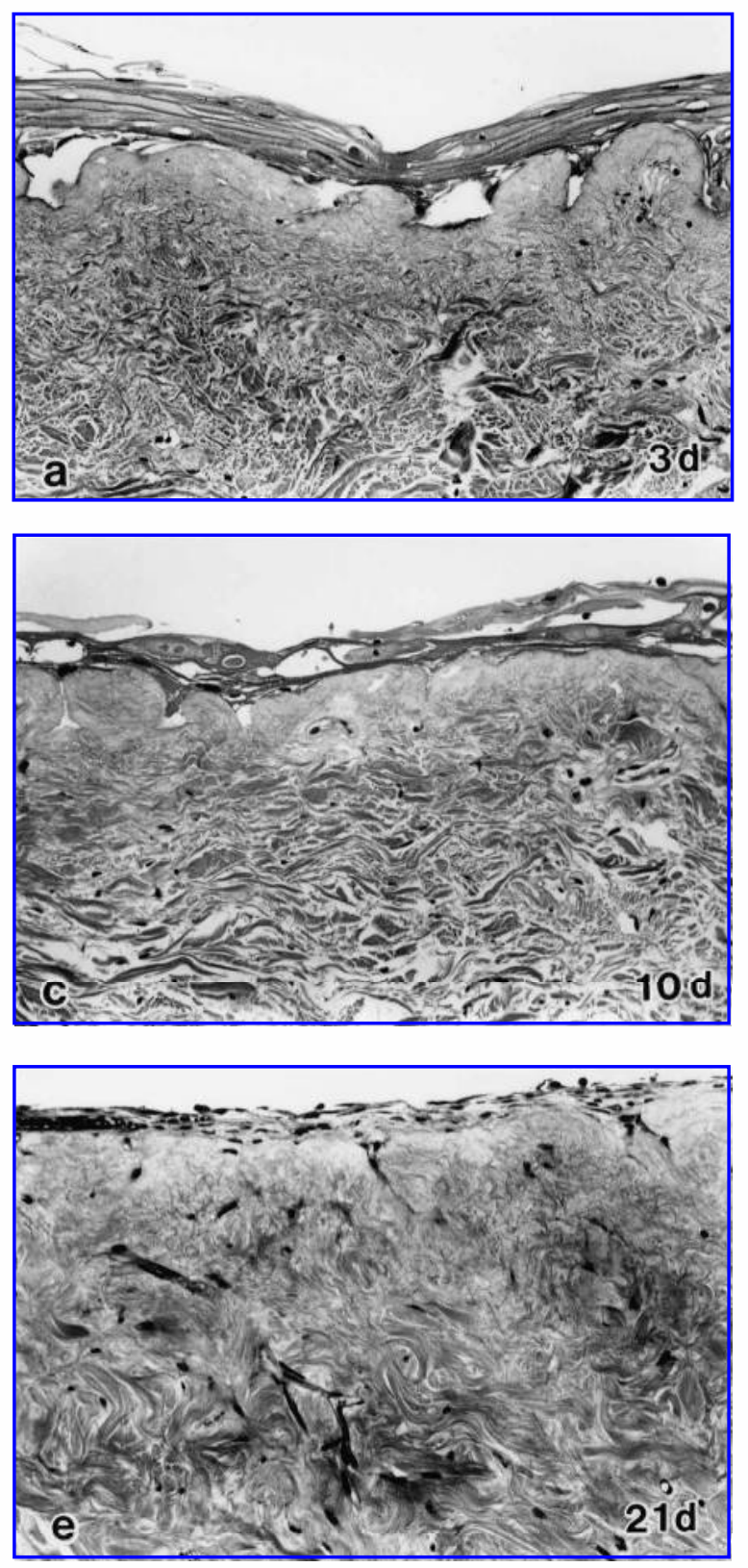

dermis (Fig. 6b). At day 10 postgrafting, D18E epithelium continued to break down (Fig. 6c). The cellular infiltration and revascularization of the entire dermis continued to show a marked increase at day 10 postgrafting (Fig. 6c and d). Arrangement of the collagen fibrils within the dermis appeared less eosinophilic and random in nature. These findings were greater than seen in D4E but
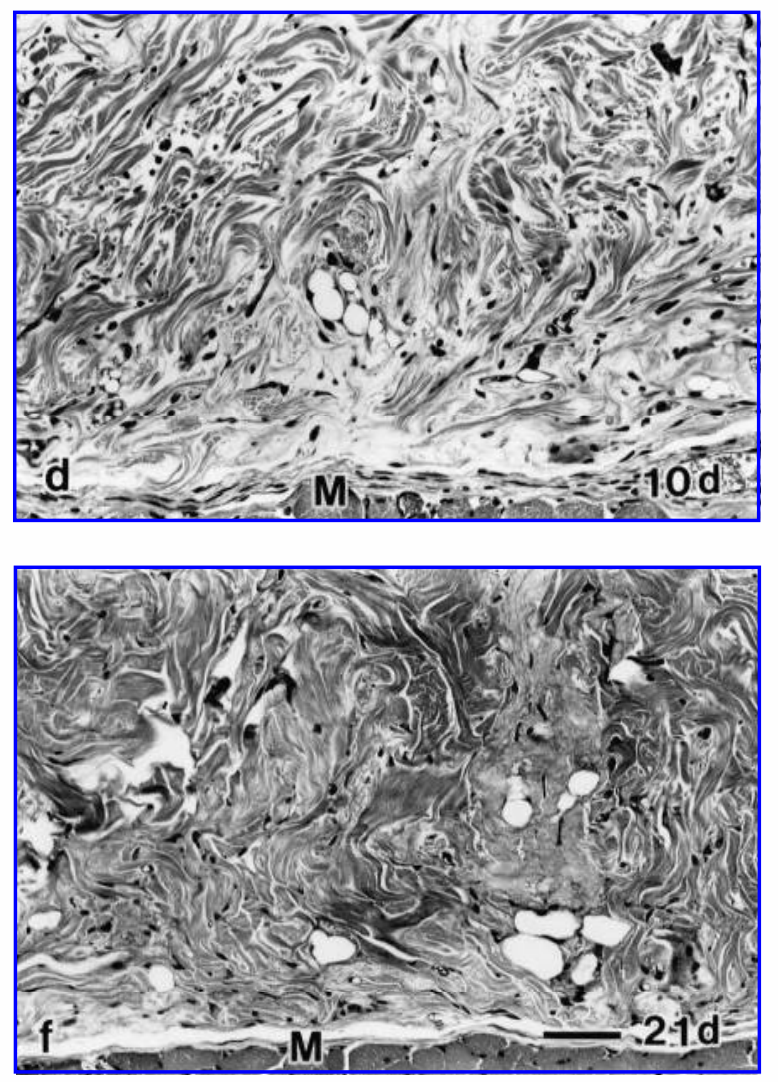

FIG. 6. Histologic analysis of grafted D18E: Postgrafting day 3 (a and b), day 10 (c and d), and day 21 (e and f); epithelial (a, c, and $\mathbf{e}$ ) and dermal (b, d, and $\mathbf{f})$ portions of the grafted equivalents. At 3 days postgrafting there was evidence of a welldifferentiated highly keratinized epithelial layer with signs of degeneration (a) associated with a cellular infiltration throughout the dermis (b). Epithelial degeneration continues to increase at day 10 postgrafting (c). Revascularization and disorganized collagen bundles of the dermis at day 10 postgrafting are evident within the lower portion of the dermis to the level seen in D11E (d). At day 21 postgrafting, the dermal matrix demonstrates linear arrays of dense collagen bundles with evidence of adiposelike tissue and marked vascularity present at base of the dermis (f). M, Underlying muscle layer. (Hematoxylin and eosin staining; original magnification, $\times 250$; scale bar, $50 \mu \mathrm{m}$.) 
the same as was seen in D11E at day 10 postgrafting. At day 21 postgrafting there were remnants of necrotic epithelium (Fig. 6e). Although lumenous structures, cellular infiltration, and revascularization were noted within the dermis the histologic appearance of collagen bundles appeared to be tighter and denser (Fig. 6f).

Immunohistochemical staining for keratin 10/13. Immunohistochemical detection of keratin 10/13 was used
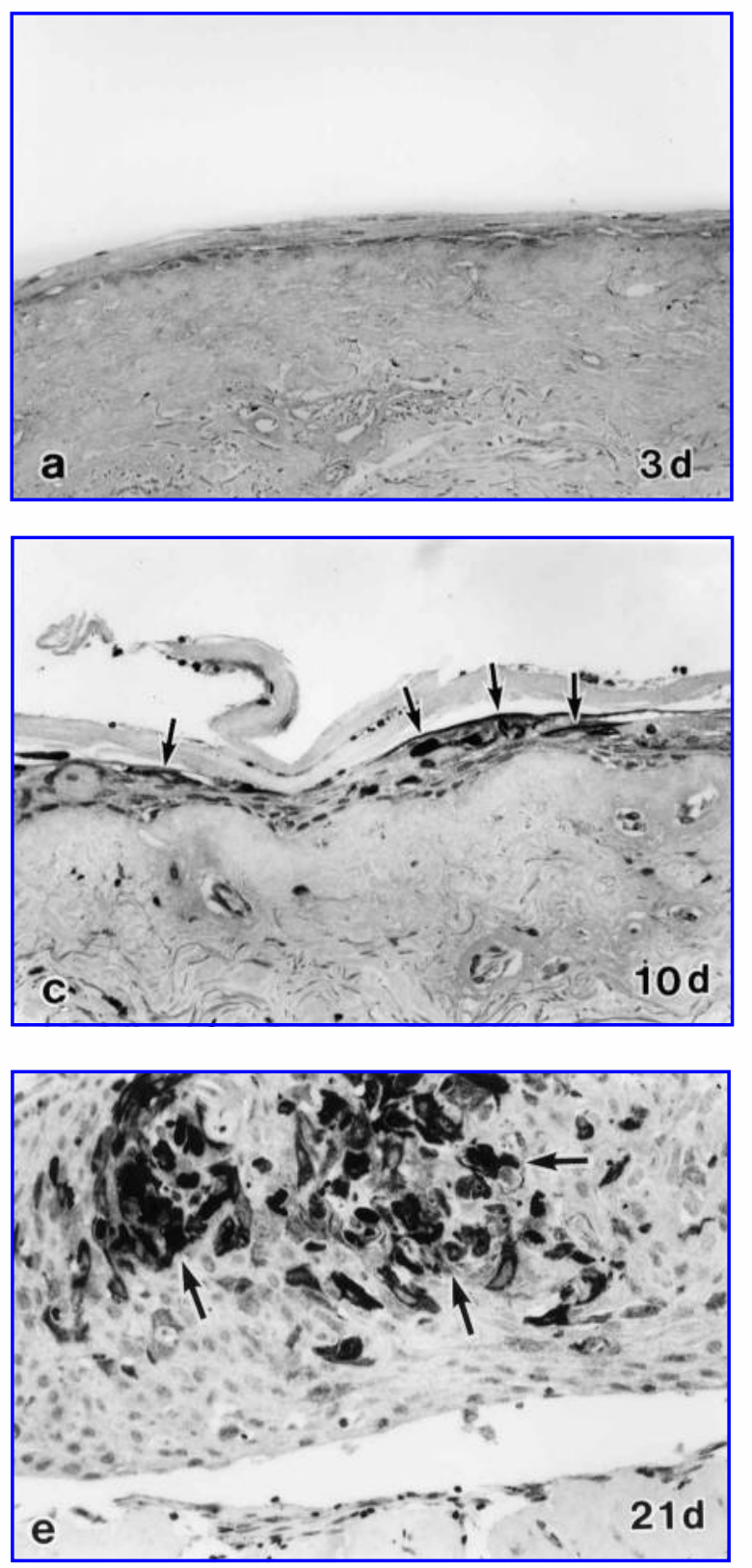

to determine the differentiated state of the epithelium after grafting in both the D4E (Fig. 7a, c, and e) and D11E (Fig. 7b, d, and f) grafted EVPOMEs at day 3, 10, and 21 days postgrafting, respectively. No evidence of keratin 10/13 was observed in D4E at postgrafting day 3 (Fig. 7a); however, expression of keratin 10/13 in D11E was seen in the superficial layer (Fig. 7b). As the epithelial layers of D4E and D11E continued to stratify at
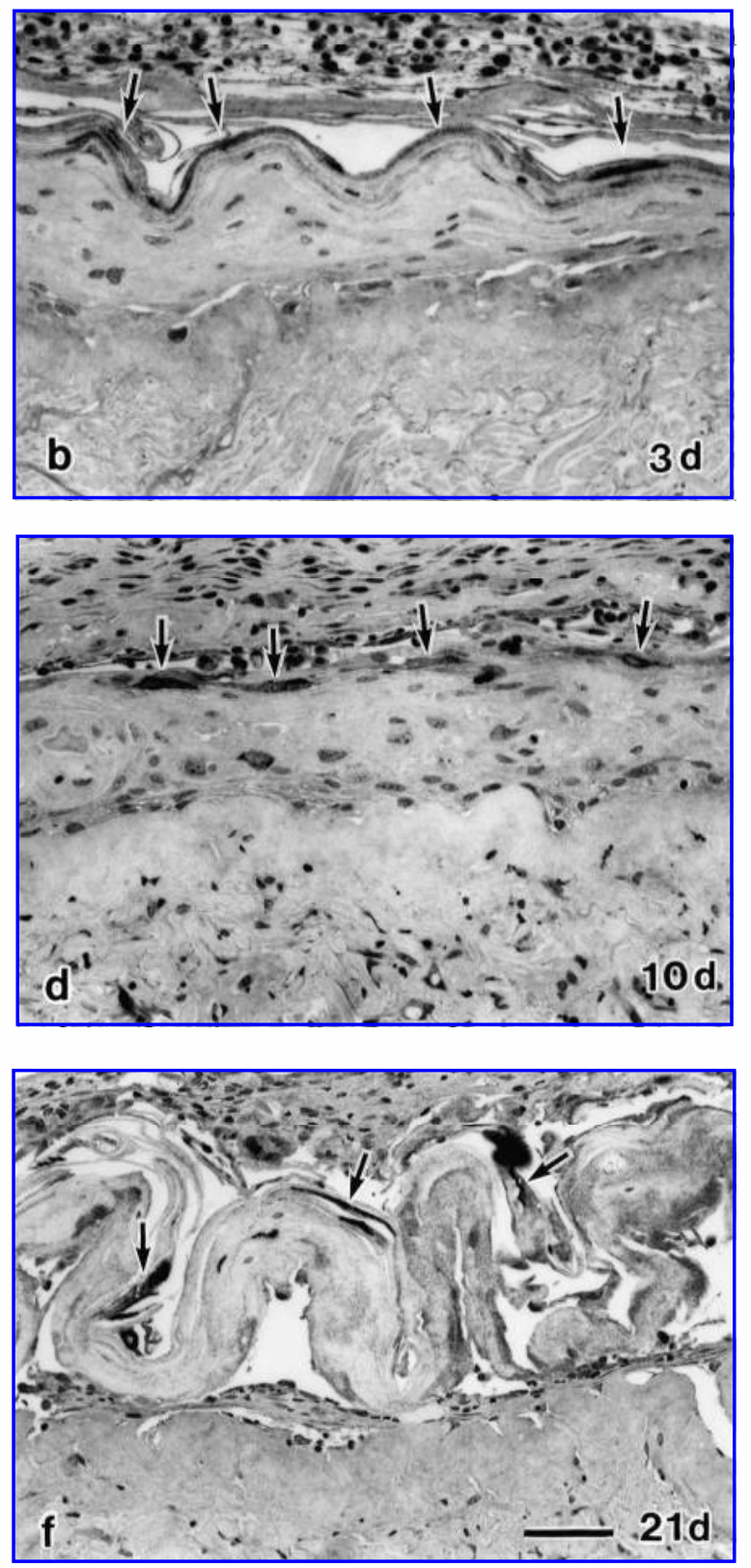

FIG. 7. Immunohistochemical analysis for the epithelial differentiation marker keratin 10/13 of grafted equivalents D4E and D11E: D4E (a, c, and e) and D11E (b, d, and f). At postgrafting day 3 (a and b), there was no evidence for staining for keratin $10 / 13$ in D4E (a), whereas the superficial layer showed keratin 10/13 expression in D11E (b) (arrows). At day 10 (c and d) and day 21 (e and $\mathbf{f}$ ) keratin 10/13 expression (arrows) increased as the epithelium continued to stratify. Expression of keratin 10/13 within the stratified epithelium in the D4E (c) was more prominent than seen in D11E (d) at day 10 postgrafting. (Immunostaining for keratin 10/13; original magnification, $\times 300$; scale bar, $50 \mu \mathrm{m}$.) 
10 and 21 days postgrafting they started to show an increase in expression of keratin 10/13 when compared with pregrafting and day 3 postgrafting equivalents (Fig. 7b-e). Expression of keratin 10/13 within the stratified epithelium in D4E (Fig. 7c) was more prominent than was seen in D11E (Fig. 7d) at day 10 postgrafting.

\section{Microvessel density}

WGA lectin binding allowed us to identify and count microvessels irrespective of the presence of erythrocytes within the lumen (Fig. 8). At day 3 postgrafting D18E showed a significant increase $(p<0.05)$ in the number of microvessels present in the dermis over the other groups, that is, D4E, D11E, and the AlloDerm without epithelium. At 10 days postgrafting, D4E, D11E, and $\mathrm{D} 18 \mathrm{E}$ all showed significantly more microvessels $(p<0.05)$ than AlloDerm without epithelium. Both D11E and D18E 10 days postgrafting showed significantly more microvessels $(p<0.05)$ when compared with D4E 10 days postgrafting. D4E continued to increase at 21 days postgrafting with a precipitous drop in the number of microvessels present in both the D11E and D18E 21 days postgrafting, which correlated with the degeneration of the epithelial layer (Table 2).

\section{DISCUSSION}

In vivo animal studies utilizing sheets of oral keratinocytes or full thickness mucosa grafts require an environment that will simulate that which is seen within the oral cavity, a moist wet-surfaced epithelium. Barrandon et al. ${ }^{19}$ reported a new technique for grafting of epithelial sheets onto the dermal surface of a flap to secure a more compatible wound bed for the epithelial grafts. Maxillofacial surgical procedures often need to cover open wounds in the oral mucosa with placement of the grafts onto the underlying muscular layer or onto the surface of free vascular muscular grafts. The animal model utilized in our study not only created a protected moist setting for the EVPOME but also allowed its placement onto the underlying muscular layer within a subcutaneous pouch of the SCID mouse, simulating a situation often seen with intraoral reconstruction procedures.

The AlloDerm portion of the EVPOME showed no evidence of an adverse inflammatory reaction or rapid remodeling reaction in the early stages after grafting but, rather, appeared to act as a biomimetic template that promoted the intradermal migration and infiltration of fibroblasts and host cells. Previous studies have shown that the concurrent grafting of a dermal component aids in enhancing the quality, and shortening the time, of wound healing and of maintaining epithelial renewal. ${ }^{22-25} \mathrm{In}$ addition, it appears important that a human dermal matrix retain a basement membrane structure as a scaffold to as-

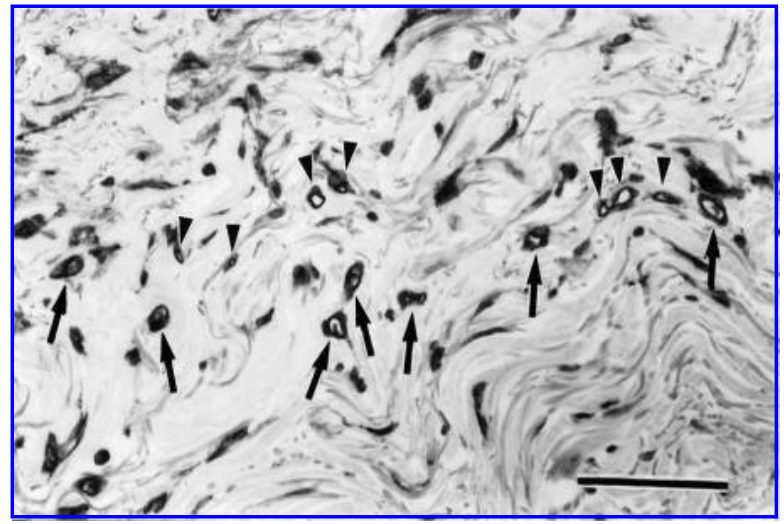

FIG. 8. Immunohistochemical detection of vascularity by ingrowth of mouse endothelial cells after grafting, using WGA lectin binding. Microvessels can be easily identified by immunohistochemical staining for WGA lectin binding whether erythrocytes are present (arrows) or not present within the lumen (arrowheads). (Immunostaining for WGA lectin; original magnification, $\times 500$; scale bar, $50 \mu \mathrm{m}$.)

sist in the optimal growth and differentiation of keratinocytes. ${ }^{23,26}$

AlloDerm with epithelium, EVPOME, showed marked remodeling of the collagenous bundles in comparison with AlloDerm without epithelium. This eventually progressed to a point of contracture of the EVPOME at 21 days postgrafting. This may be secondary to the way in which the EVPOME was secured, without the benefit of sutures onto a mobile underlying muscular-connective tissue base. In addition, cultured keratinocytes are capable of contracting the acellular dermis by secretion of enzymes that are initiated by infiltrating mesenchymal fibroblastic cells into the underlying dermis via paracrine pathways. ${ }^{27}$ Epithelial detachment seen in D4E and the undulated epithelial layer of D11E, at postgrafting day

Table 2. Microvessel Count within EVPOME over Time after Grafting ${ }^{a}$

\begin{tabular}{lccc}
\hline & \multicolumn{3}{c}{ Days postgrafting } \\
\cline { 2 - 4 } & \multicolumn{1}{c}{3} & \multicolumn{1}{c}{10} & 21 \\
\hline Control $^{\mathrm{b}}(n=5)$ & $1.2 \pm 0.4$ & $2.6 \pm 0.4$ & $11.2 \pm 3.6$ \\
$\mathrm{D} 4 \mathrm{E}(n=15)$ & $1.7 \pm 0.2$ & $15.5 \pm 5.0^{\mathrm{c}}$ & $26.0 \pm 5.4$ \\
$\mathrm{D} 11 \mathrm{E}(n=10)$ & $2.4 \pm 0.6$ & $69.7 \pm 7.5^{\mathrm{c}, \mathrm{d}}$ & $19.2 \pm 1.9$ \\
$\mathrm{D} 18 \mathrm{E}(n=10)$ & $3.0 \pm 0.2^{\mathrm{c}, \mathrm{d}}$ & $68.6 \pm 10.7^{\mathrm{c}, \mathrm{d}}$ & $28.5 \pm 5.1^{\mathrm{c}}$ \\
\hline
\end{tabular}

Abbreviations:D4E, D11E, and D18E: day 4, day 11, and day 18 equivalents, respectively; EVPOME, ex vivo-produced and oral mucosa equivalent.

${ }^{a}$ Values represent means \pm SEM.

${ }^{\mathrm{b}}$ AlloDerm without an epithelial layer.

${ }^{\mathrm{c} S}$ Significantly different from control at $p<0.05$.

${ }^{\mathrm{d}}$ Significantly different from D4E at $p<0.05$. 
21 , could be secondary to this cellular process resulting in dermal contraction.

After the initial 2 to 3 days postgrafting, two pathways of vascularity determine posttransplantation viability of the grafted tissue. Vascularity of the free grafts can occur through inosculation, the "hook up" or anastomosis of newly ingrown host vessels into preexisting vessels present in the grafted or transplanted tissue, ${ }^{28,29}$ or by neovascularization, the growth of completely new capillaries from the recipient bed into the graft. Young and others ${ }^{29}$ showed that the initial vascularization of skin grafts is solely the result of inosculation rather than neovascularization. Blood vessels filled with erythrocytes were frequently seen within the dermal component, AlloDerm, in D11E and D18E at postgrafting day 10. One of the unique properties of AlloDerm is the retention of the original, intact blood vessel channels even after its processing. ${ }^{30}$ These residual walls and lumens of the blood vessels within the AlloDerm can act as a template or conduit to enhance migration of endothelial cells to form intact vessels to the EVPOME. ${ }^{30,31}$ The threedimensional network structure of AlloDerm has the advantage of reestablishing vascular flow within the dermis by virtue of both inosculation and neovascularization.

Several studies have shown that a dermal substrate influences growth of keratinocytes. ${ }^{6,26,30,32-34}$ In our study, the results demonstrate that the presence of a healthy and intact epithelial layer on the EVPOME enhanced vascular infiltration into the underlying dermis when compared with the control samples, AlloDerm without epithelium, which showed less fibroblastic infiltration and vessel lumen formation (Table 2). In addition, the different patterns of vascular ingrowth seen within the dermal layer of the three types of EVPOME, D4E, D11E, and D18E, are thought to be related to the number and stage of differentiation of the overlying keratinocytes.

Several studies have shown that vascular endothelial growth factor (VEGF) secreted by keratinocytes plays a role in fibrovascular ingrowth. ${ }^{35-37}$ Viac and others ${ }^{37}$ showed that VEGF expression in the epithelium could be modified according to the stage of cell differentiation and during rapid growth or activation of keratinocytes. In cultured keratinocytes, the amount of cell-associated and secreted VEGF increased with time, and was released extracellularly, after its production (data not shown). The gradual increase in epithelial stratification and expression of the epithelial differentiation marker, keratin $10 / 13$, in the suprabasal layer in both D4E and D11E, at day 21 postgrafting, is consistent with previous reports that show expression of several differentiation markers in the suprabasal layer cells of skin composites composed of acellular dermis after grafting. ${ }^{38,39}$ Although we did not examine transplants more than 21 days postgrafting, it is noteworthy that no keratin 10/13 expression was seen within keratinocytes on EVPOME before grafting. The expression of keratin 10/13 within the epithelial layer became evident only after grafting in situ within SCID mice. This implied that the epithelial layer of D4E and D11E possessed a hyperproliferative and long-term replicative cell population even after transplantation into SCID mice. The stratified keratinocytes in D4E expressed keratin $10 / 13$ sooner and stronger than in D11E.

In conclusion, the presence of an intact and viable epithelial layer influenced secondary remodeling within the dermis of the EVPOME, most likely by its synthesis and release of cytokines, enzymes, and growth factors. Although the survival and thickness of overlying epithelium, in vivo, depended on the length of time of in vitro culturing of the EVPOME at an air-liquid interface, it appears that D11E contained the optimal balance of revascularity and epithelial activity. The advantage of using D11E for grafting is its shorter culture period to produce equivalents 1 week relative to $\mathrm{D} 18 \mathrm{E}$, without compromising on epithelial stratification and without a decrease in fibrovascular ingrowth within the dermis. The advantage of D11E over D4E is the increased stratification of the epithelium seen in D11E, resulting in enhanced vascularity of the underlying dermal component after grafting is situ.

\section{ACKNOWLEDGMENTS}

The authors thank Lenore M. Rhodes and Masaaki Hoshino for technical assistance. This investigation was funded by NIH grant DE 13417 (S.E.F.) and a University of Michigan School of Dentistry Seed Grant (S.E.F.).

\section{REFERENCES}

1. O’Conner, N.E., Mulliken, J.B., Banks-Schlegel, S., Kehinde, O., and Green, H. Grafting of burns with cultured epithelium prepared from autologous epidermal cells. Lancet 1, 75, 1981.

2. Gallico, G.G., O’Conner, N.E., Compton, C.C., Kehinde, O., and Green, H. Permanent coverage of large burn wounds with autologous cultured human epithelium. N. Engl. J. Med. 311, 448, 1984.

3. Gallico, G.G., O’Conner, N.E., Compton, C.C., Kehinde, O., and Green, H. Cultured epithelial autografts for giant congenital nevi. Plast. Reconstr. Surg. 84, 1, 1989.

4. Hefton, J.M., Caldwell, D., and Biozes, D.G. Grafting of skin ulcers with cultured autologous epidermal cells. J. Am. Acad. Dermatol. 14, 399, 1986.

5. Cuono, C., Langdon, R., and McGuire, J. Use of cultured epidermal autografts and dermal allografts as skin replacement after burn injury. Lancet 327, 1123, 1986.

6. Kangesu, T., Navsaria, H.A., Manek, S., Fryer, P.R., Leigh, I.M., and Green, C.J. Kerato-dermal grafts: The importance 
of dermis for the in vivo growth of cultured keratinocytes. Br. J. Plast. Surg. 46, 401, 1993.

7. Burke, J.F., Yannas, I.V., Quinby, W.C., Jr., Bondoc, C.C., and Jung, W.K. Successful use of a physiologically acceptable artificial skin in the treatment of extensive burn injury. Ann. Surg. 194, 413, 1981.

8. Compton, C.C., Butler, C.E., Yannas, I.V., Warland, G., and Orgill, D.P. Organized skin structure is regenerated in vitro from collagen-GAG matrices seeded with autologous keratinocytes. J. Invest. Dermatol. 110, 908, 1998.

9. Gustafson, C.-J., and Kratz, G. Cultured autologous keratinocytes on a cell-free dermis in the treatment of fullthickness wounds. Burns 25, 331, 1999.

10. Cooper, M.L., and Hansbrough, J.F. Use of a composite skin substitute containing human keratinocytes and fibroblasts and a collagen-GAG matrix to cover full-thickness wounds on athymic mice. Surgery 109, 198, 1991.

11. Parenteau, N.L., Nolte, C.M., Bilbo, P., et al. Epidermis generated in vitro: Practical considerations and applications. J. Cell. Biochem. 45, 245, 1991.

12. Hansbrough, J.F., Morgan, J., Greenleaf, G., Parikh, M., Nolte, C., and Wilkins, L. Evaluation of graftskin composite grafts on full-thickness wounds on athymic mice. $\mathrm{J}$. Burn Care Rehabil. 15, 346, 1994.

13. Krejci, N.C., Cuono, C.B., Langdon, R.C., and McGuire, J. In vitro reconstitution of skin: Fibroblasts facilitate keratinocyte growth and differentiation on acellular reticular dermis. J. Invest. Dermatol. 97, 843, 1991.

14. Rikimaru, K., Mols, J.-P., and Watt, F.M. Correlation between hyperproliferation and suprabasal integrin expression in human epidermis reconstituted in culture. Exp. Dermatol. 6, 214, 1997.

15. $\overline{C h u n g}$, J.H., Cho K.H., Lee, D.Y., Kwon, O.S., Sung, M.-W., Kim K.H., and Eun, H.C. Human oral buccal mucosa reconstructed on dermal substrates: A model for oral epithelial differentiation. Arch. Dermatol. Res. 289, 677, 1997.

16. Izumi, K., Takacs, G., Terashi, H., and Feinberg, S.E. Ex vivo development of a composite human oral mucosal equivalent. J. Oral. Maxillofac. Surg. 57, 571, 1999.

17. Cho, K.H., Ahn, H.T., Park, K.C., et al. Reconstruction of human hard-palate mucosal epithelium on de-epidermized dermis. J. Dermatol. Sci. 22, 117, 2000.

18. Izumi, K., Terashi, H., Marcelo, C.L., and Feinberg, S.E. Development and characterization of a tissue-engineered human oral mucosa equivalent produced in a serum-free culture system. J. Dent. Res. 79, 798, 2000.

19. Barrandon, Y., Li, V., and Green, H. New techniques for the grafting of cultured human epidermal cells onto athymic mice. J. Invest. Dermatol. 91, 315, 1988.

20. Alroy, J., Goyal, V., and Skutelsky, E. Lectin histochemistry of mammalian endothelium. Histochemistry 86, 603, 1987.

21. Weidner, N., Semple, J.P., Welch, W.R., and Folkman, J. Tumor angiogenesis and metastasis-correlation in invasive breast carcinoma. N. Engl. J. Med. 324, 1, 1991.

22. Feinberg, S.E., Krishnan, V., Gordillo, G., and Shuler, C.F. Intraoral grafting of a canine full-thickness oral mucosal equivalent produced in vitro. J. Oral Maxillofac. Surg. 47, $712,1989$.
23. Navsaria, H.A., Kangesu, T., Manek, S., Green, C.J., and Leigh, I.M. An animal model to study the significance of dermis for grafting cultured keratinocytes on full thickness wound. Burns 20, S57, 1994.

24. Leary, T., Jones, P.L., Appleby, M., Blight, A., Parkinson, K., and Stanley, M. Epidermal keratinocyte self-renewal is dependent upon dermal integrity. J. Invest. Dermatol. 99, 422, 1991.

25. Auger, F.A., Lopez Valle, C.A., Guignard, R., Tremblay, N., Noel, B., Goulet, F., and Germain, L. Skin equivalent produced with human collagen. In Vitro Cell Dev. Biol. Anim. 31, 432, 1995.

26. Cooper, M.L., Andree, C., Hansbrough, J.F., ZapataSirvent, R.L., and Spielvogel, R.L. Direct comparison of a cultured composite skin substitute containing human keratinocytes and fibroblasts to an epidermal sheet graft containing human keratinocytes on athymic mice. J. Invest. Dermatol. 101, 811, 1993.

27. Ralston, D.R., Layton, C., Dalley, A.J., Boyce, S.G., Freedlander, E., and MacNeil, S. Keratinocytes contract human dermal extracellular matrix and reduce soluble fibronectin production by fibroblasts in a skin composite model. Br. J. Plast. Surg. 50, 408, 1997.

28. Demarchez, M., Hartmann, D.J., and Prunieras, M. An immunohistochemical study of the revascularization process in human skin transplanted onto the nude mouse. Transplantation 43, 896, 1987.

29. Young, D.M., Greulich, K.M., and Weier, H.G. Speciesspecific in situ hybridization with fluorochrome-labeled DNA probes to study vascularization of human skin grafts on athymic mice. J. Burn Care Rehabil. 17, 305, 1996.

30. Livesey, S.A., Herndon, D.N., Hollyoak, M.A., Atkinson, Y.H., and Nag, A. Transplanted acellular allograft dermal matrix: Potential as a template for the reconstruction of viable dermis. Transplantation 60, 1, 1995.

31. Medalie, D.A., Eming, S.A., Tompkins, R.G., Yarmush, M.L., Krueger, G.G., and Morgan, J.R. Evaluation of human skin reconstituted from composite grafts of cultured keratinocytes and human acellular dermis transplanted to athymic mice. J. Invest. Dermatol. 107, 121, 1996.

32. Compton, C.C., Hickerson, W., Nadire, K., and Press, W. Acceleration of skin regeneration from cultured epithelial autografts by transplantation to homograft dermis. J. Burn Care Rehabil. 14, 653, 1993.

33. Wainwright, D.J. Use of an acellular allograft dermal matrix $\left(\right.$ AlloDerm $\left.{ }^{\circledR}\right)$ in the management of full-thickness burns. Burns 21, 243, 1995.

34. Lopez Valle, C.A., Germain, L., Rouabhia, M., Xu, W., Guignard, R., Goulet, F., and Auger, F.A. Grafting on nude mice of living skin equivalents produced using human collagens. Transplantation 62, 317, 1996.

35. Frank, S., Hübner, G., Breier, G., Longaker, M.T., Greenhalgh, D.G., and Werner, S. Regulation of vascular endothelial growth factor expression in cultured keratinocytes. J. Biol. Chem. 270, 12607, 1995.

36. Eming, S.A., Lee, J., Snow, R.G., Tompkins, R.G., Yarmush, M.L., and Morgan, J.R. Genetically modified human epidermis overexpressing PDGF-A directs the development of a cellular and vascular connective tissue stroma 
when transplanted to athymic mice: Implications for the use of genetically modified keratinocytes to modulate dermal regeneration. J. Invest. Dermatol. 105, 756, 1995.

37. Viac, J., Palacio, S., Schmitt, D., and Claudy, A. Expression of vascular endothelial growth factor in normal epidermis, epithelial tumors and cultured keratinocytes. Arch. Dermatol. Res. 289, 158, 1997.

38. Higounenc, I., Demarchez, M., Regnier, M., Schmit, R., Ponec, M., and Shroot, B. Improvement of epidermal differentiation and barrier function in reconstructed human skin after grafting onto athymic nude mice. Arch. Dermatol. Res. 286, 107, 1994.

39. Medalie, D.A., Tompkins, R.G., and Morgan, J.R. Evalu- ation of acellular human dermis as a dermal analog in a composite skin grafts. ASAIO J. 42, M455, 1996.

Address reprint requests to: Stephen E. Feinberg, D.D.S., Ph.D. Department of Oral and Maxillofacial Surgery University of Michigan Medical Center B1-A235 UH, Box 0018 1500 East Medical Center Drive Ann Arbor, MI 48109-0018

E-mail: sefein@umich.edu 


\section{This article has been cited by:}

1. I. Garzón, M. C. Sánchez-Quevedo, G. Moreu, M. González-Jaranay, M. González-Andrades, A. Montalvo, A. Campos, M. Alaminos. 2009. In vitro and in vivo cytokeratin patterns of expression in bioengineered human periodontal mucosa. Journal of Periodontal Research . [CrossRef]

2. Michael S. Stosich , Barb Bastian, Nicholas W. Marion, Paul A. Clark, Gwendolen Reilly , Jeremy J. Mao . 2007. Vascularized Adipose Tissue Grafts from Human Mesenchymal Stem Cells with Bioactive Cues and Microchannel ConduitsVascularized Adipose Tissue Grafts from Human Mesenchymal Stem Cells with Bioactive Cues and Microchannel Conduits. Tissue Engineering 13:12, 2881-2890. [Abstract] [PDF] [PDF Plus]

3. Norman M. Rowe, Luc Morris, Mark D. Delacure. 2006. Acellular Dermal Composite Allografts for Reconstruction of the Radial Forearm Donor Site. Annals of Plastic Surgery 57:3, 305-311. [CrossRef]

4. Christopher Hrabchak, Lauren Flynn, Kimberly A Woodhouse. 2006. Biological skin substitutes for wound cover and closure. Expert Review of Medical Devices 3:3, 373-385. [CrossRef]

5. Junhui Song, Kenji Izumi, Thomas Lanigan, Stephen E. Feinberg. 2004. Development and characterization of a canine oral mucosa equivalent in a serum-free environment. Journal of Biomedical Materials Research 71A:1, 143-153. [CrossRef] 